\title{
A perennial invader's seed and rhizome differ in cold tolerance and apparent local adaptation
}

\author{
Vasiliy T. Lakoba', Gregory E. Welbaum², John R. Seiler ${ }^{3}$ Jacob N. Barney' \\ I School of Plant and Environmental Sciences, Virginia Tech, 675 Old Glade Road, Blacksburg, Virginia, USA \\ 2 School of Plant and Environmental Sciences, Virginia Tech, 1880 Pratt Drive, Blacksburg, Virginia, USA \\ 3 Department of Forest Resources and Environmental Conservation, Virginia Tech, 310 West Campus Drive, \\ Blacksburg, Virginia, USA \\ Corresponding author: Vasiliy T. Lakoba (vtlakoba@vt.edu)
}

Academic editor: E. Wandrag | Received 18 February 2021 | Accepted 12 August 2021 | Published 16 November 2021

Citation: Lakoba VT, Welbaum GE, Seiler JR, Barney JN (2021) A perennial invader's seed and rhizome differ in cold tolerance and apparent local adaptation. NeoBiota 70: 1-21. https://doi.org/10.3897/neobiota.70.64614

\begin{abstract}
Extreme cold plays a key role in the range boundaries of plants. Winter survival is central to their persistence, but not all structures are equally susceptible to frost kill and, therefore, limiting to distributions. Furthermore, we expect intraspecific variation in cold tolerance both within and among tissue types. In a laboratory setting, we determined freezing tolerances of two overwintering propagule types - seeds and rhizomes - of the globally invasive Johnsongrass (Sorghum halepense), testing apparent emergence and electrolyte leakage as a proxy for cell death. We used 18 genotypes from agricultural and non-agricultural habitats spanning the climatic extremes occupied by Johnsongrass in the US. Single node rhizome fragments had an average LT90 of $-5.1{ }^{\circ} \mathrm{C}$ with no significant variation based on home climate or ecotype. Seeds frozen at $-85^{\circ} \mathrm{C}$ suffered a decline in germinability to $10 \%$ from $25 \%$ at $22{ }^{\circ} \mathrm{C}$. Population origin did not affect seed response to any temperature. However, non-agricultural seeds germinated more and faster than agricultural seeds from the coldest climates, with a reversed relationship among warmest origin seeds. Regardless of ecotype, seeds from the cold/dry and wet/warm sectors of Johnsongrass's range germinated more and faster. Drastic differences in cold tolerance between seeds and rhizome and evidence for seeds' local adaptation to land use and climate suggest that its spread is likely limited by winter rhizome survival, as well as adaptability of germination behavior to longer winters. These findings shed light on Johnsongrass' dispersal dynamics and help identify future avenues for mechanistically understanding its range limitation.
\end{abstract}

\section{Keywords}

Cold tolerance, invasive plants, land use change, local adaptation, range boundaries

Copyright Vasiliy T. Lakoba et al. This is an open access article distributed under the terms of the Creative Commons Attribution License (CC BY 4.0), which permits unrestricted use, distribution, and reproduction in any medium, provided the original author and source are credited. 


\section{Introduction}

Species range limits are often dictated by climatic tolerances at large spatial scales. For most plants, temperature and moisture availability play a leading, though not unilateral, role in defining distributions (Curtis and Bradley 2016). To characterize how specific temperature or moisture parameters (e.g., extremes, durations, seasonality) limit a plant's range, empirical methods and spatial models are typically used (Kotta et al. 2019; Greiser et al. 2020). In the temperate biomes of the northern hemisphere, cold winter temperatures play a role in limiting some perennial plants' northern range boundaries, but are not sole drivers, interacting with growing season conditions that shape overwintering tissue maturation (Körner et al. 2016). While winter survival is measured at the whole-plant level, it is important to consider that a variety of organs (e.g., roots, herbaceous or woody shoots) may be responsible for cold tolerance to different degrees (Washburn et al. 2013; Sage et al. 2015; Ambroise et al. 2020). This means that distribution modeling based only on species presence is not sufficient to mechanistically identify cold tolerance limits (Gardner et al. 2019), especially in herbaceous perennials which often look similar in each season of their lifespan. Specifically, summer presence of such a species does not necessarily indicate survival through the previous winter, but potentially successful re-establishment from seed. This, in turn, muddles our understanding of how the plant and its constituent tissues respond to freezing temperatures. Cold tolerance is often considered at the organismal level, but testing different organs separately is most appropriate, particularly for perennial plants.

Both sexual and vegetative structures need cold tolerance to survive between growing seasons in non-tropical climates. While individual perennation is dependent on winter cold tolerance (Sage et al. 2015), sexual reproduction is dependent on annual seed production, dispersal, and establishment. In many temperate species, the winter season also intercedes between seed abscission and germination, requiring seed cold tolerance (Leiblein-Wild et al. 2014). Given the importance of cold tolerance to both survival and reproduction - and, therefore, overall fitness - its parameters (e.g, lethal temperature estimates) can be projected onto spatial climate patterns to hypothesize, though not predict, range limits (Sánchez-Fernández et al. 2012; Gardner et al. 2019). The strength of this approach is not in accurately and causally predicting distribution (which is better served by correlative modeling of multiple drivers), but in understanding the locations at which the specific stressor (i.e., temperature) is or is not likely to limit distribution.

Perenniality is a boon to plant fitness because it reduces each subsequent year's demand for vegetative-to-reproductive allocation (Rohde and Bhalerao 2007). However, this requires major structural (e.g., xylogenesis) and non-structural carbohydrate production (Kozlowski 1992; Slewinski 2012), whose storage is mediated by winter minimum temperatures ( $\mathrm{Li}$ et al. 2017). This is a key to some plants' persistence through seasonal energy reallocation and storage in rhizome tissue (Boström et al. 2013). Across climate gradients, conditions acting on perennial tissue survival select for locally hardy (i.e., cold tolerant) genotypes (Malyshev et al. 2014; Dong et al. 2019). This selection can be driven not only by macroclimates, but also by anthropogenically-induced 
microclimates (e.g., irrigated fields, urban heat islands, etc.) and resource subsidies (Charrier et al. 2015; Oraee et al. 2020).

Perenniality can also buffer against challenging growing conditions (e.g., cold winter temperatures, Wingler 2015), and therefore impact species distribution. An important link between perenniality, fitness, and distributions is dispersal capability, which we can better understand by comparing propagules of varying anatomy, stress tolerance, and transportability (e.g., seed vs. rhizome). Thus, if local climates and habitats (i.e., provenance) select for biologically significant differences in cold tolerance and perenniality, this raises two questions. Firstly, could ranges suitable for vegetative propagation be more provenance-limited than ranges suitable for seed propagation? Secondly, if habitat type impacts perenniality via cold tolerance, could species distribution be mediated by land use as a selection pressure? These two questions have not been explicitly studied, but we might anticipate many interactions between land management and adaptation in current and future climates (Ramesh et al. 2017; Weber et al. 2017).

Advantages of having rhizomes (perennial underground stems) are evident across many plant systems (e.g., Chen et al. 2015; Grewell et al. 2019). In particular, rhizomes are a common feature of invasive species, which lend themselves well to the study of range limits and stress tolerance due to high data availability and ease of propagation. For example, some perennial invaders are able to maintain their competitive edge in recipient communities despite initial reductions in growth due to rhizome fragmentation (Zhou et al. 2017). In other cases, perennial invasive plants emerging from rhizomes are more competitive and stress tolerant than conspecific seedlings (Mitskas et al. 2003; Acciaresi and Guiamet 2010). Other forms of modified perennial stems, such as stolons, are believed to buffer invasive plants from stress and promote colonial expansion (Roiloa and Retuerto 2016). For instance, Pompeiano et al. (2015) found metabolic adjustment of sugar and proline concentration across all organs of the rhizomatous invader Arundo donax to explain differences in cold hardiness between Hungarian and Honduran populations. Studying populations from across a climate gradient, Dietrich et al. (2018) found Dactylis glomerata rhizome cold tolerance to correlate negatively with mean precipitation at home habitats across Europe. However, it remains unclear which climate and habitat factors drive variation in rhizomatousness in perennial invasive plants, and whether these species may forgo perenniality to colonize more challenging ranges. To address this, we used a model perennial invasive grass to evaluate the effects of climate and habitat on both rhizome and seed cold tolerance.

The cosmopolitan invader Johnsongrass (Sorghum halepense) sexually reproduces annually through seed, while its perenniality is achieved by rhizome survival through the winter (Washburn et al. 2013). It has been estimated that a single Johnsongrass genet can produce 33,600 kg ha-1 of rhizome annually (McWhorter 1972). The perpropagule establishment efficiency of rhizome over seed is another factor in its importance to the invader's persistence (Atwater et al. 2017). At Johnsongrass's northern range edge in southern Ontario, there are reported persistent annual populations which are presumed to be caused by failure of winter rhizome survival (Warwick and Black 1983). Given the abundant evidence for great intraspecific variation in Johnsongrass 
(Atwater et al. 2016, 2017; Sezen et al. 2016), it appears likely that large differences in minimum temperature across this plant's U.S. range could have led to local adaptation of rhizome cold tolerance based on climate.

Rhizome cold tolerance may also be related to overall rhizome development, which responds to resource inputs. Fertilization and irrigation can be responsible for rhizome development changes compared to growth in non-agricultural settings (Schmid and Bazzaz 1992; Schwinning et al. 2017), therefore selection may be different in cropland habitats where more rhizome biomass is generated than in more stress-associated non-agricultural environments. This advantage in growing season resources may buffer against winter kill, similar to the way that trees rely on tissue maturation to survive freezing temperatures (Körner et al. 2016).

Specific to Johnsongrass, Atwater et al. (2017) found that, while seed was more efficient at reproducing than rhizome on a per-unit-carbon basis, rhizome was more efficient than seed per propagule. The same study found Johnsongrass plants emerging from rhizome fragments to be more sensitive to habitat variation, competition, and density than seedlings. In addition, there has been abundant evidence of ecotypic differences interacting with home climate and response to competition in Johnsongrass in the United States (Atwater et al. 2016). These pieces of information suggest that the species' different reproductive allocation strategies could be mediated by habitat type. However, no studies had isolated winter rhizome survival - on which the invader's perenniality depends - as affected by home climate or habitat. Fletcher et al (unpublished data) found populations from across the U.S. range to be incapable of winter survival at the northern range edge (Ithaca NY) regardless of ecotype, as opposed to 100\% survival in Virginia, Texas, and New Mexico. Home climate- and ecotype-based differences in Johnsongrass's perenniation have remained an important knowledge gap. Combining our awareness of photosynthetic differences between agricultural and non-agricultural populations (Kelly et al. 2020; Lakoba and Barney 2020) and tissue maturation's role in cold tolerance (Körner et al. 2016), we chose to test for ecotypic differences in seed and rhizome cold tolerance.

In the broader context of plant invasion biology, we set out to test whether adaptation to different land uses can yield divergent stress adaptation in a relatively short period of time (i.e., decades to centuries). While other studies have investigated differences between geographic ecotypes and home climates as predictors of perennial plant cold tolerance (Pompeiano et al. 2015; Dietrich et al. 2018), ours is the first to compare climate origin with land use origin. To address this research gap, we subjected populations of agricultural and non-agricultural Johnsongrass ecotypes representing a wide range of home climates to sub-zero temperatures to evaluate rhizome and seed cold tolerance. Specifically, we wanted to know whether: 1) populations from colder and/or drier climates exhibit greater cold tolerance; 2) populations from non-agricultural habitats exhibit greater cold tolerance due to the lack of agricultural inputs aiding growth and non-structural carbohydrate storage; 3 ) cold tolerance trends within and among populations differ between seeds and rhizomes. The findings will help us further understand the implications of habitat switching in Johnsongrass as well as offer a new link between land use change, climate, and invasive species. 


\section{Methods}

\section{Population selection}

We sourced propagules from our collection of $>200$ Johnsongrass populations representing the full geographic and climatic variation of its US range. In particular, we drew from a subset of this collection that consisted of seed produced in a common garden setting to account for maternal effects. For this study, we systematically chose populations representing both agricultural and non-agricultural origins, as well as the extremes of mean annual precipitation (MAP) and minimum January temperature (MinT), each averaged across a 30-year span (1981-2010). We used MAP to account for general moisture availability, which interacts with temperature, but is not the focus of our stress tolerance study. However, we chose January MinT as a proxy for the extreme cold experienced at a given location, which may correspond more directly with adapted cold tolerance rather than the annual mean (Curtis and Bradley 2016; Bishop et al. 2017). MAP and MinT values for each population's geographic origin were obtained from PRISM Climate Group (Oregon State University) using ArcMap 10.5.1 (ArcGIS Desktop: Release 10. Redlands, CA: Environmental Systems Research Institute). Agricultural and non-agricultural populations were plotted separately in climate space (MAP vs. MinT). Home habitat MAP values ranged from $195 \mathrm{~mm}$ to $1480 \mathrm{~mm}$ for agricultural populations and $198 \mathrm{~mm}$ to $1540 \mathrm{~mm}$ for non-agricultural populations. Home habitat MinT values ranged from $-7.9{ }^{\circ} \mathrm{C}$ to $5.2^{\circ} \mathrm{C}$ for agricultural populations and $-9.4^{\circ} \mathrm{C}$ to $4.3{ }^{\circ} \mathrm{C}$ for non-agricultural populations. We chose 12 populations of agricultural and non-agricultural origin (24 total) from the periphery (extremes) of the MAP vs. MinT plot (see Fig. 1). Of these,

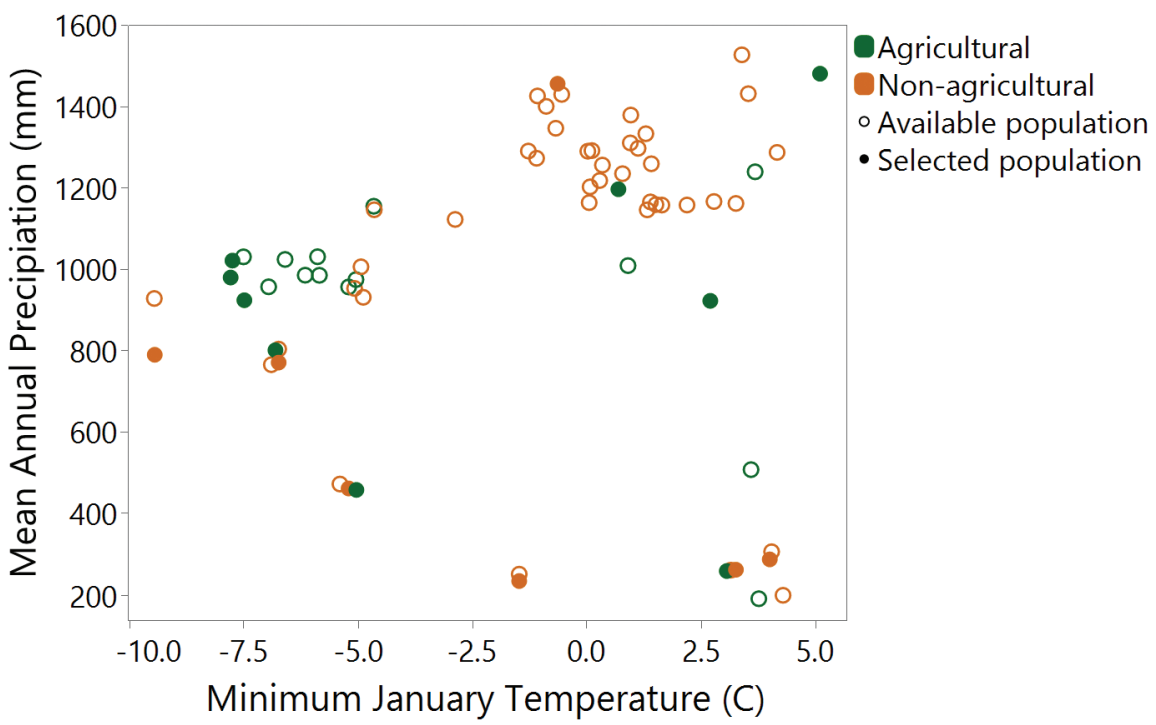

Figure I. The Johnsongrass populations selected for the rhizome and seed experiments (see details in Table 1) plotted in climate space. 
Table I. A complete list of the Johnsongrass populations used in the seed freezing and rhizome freezing experiments. The ecotype source and the population is indicated, as well as the 30-year normal of mean annual precipitation (MAP) and minimum January temperature (MinT).

\begin{tabular}{lccccc}
\hline \multicolumn{1}{c}{ Population } & Ecotype & MAP $(\mathbf{m m})$ & MinT $\left({ }^{\circ} \mathbf{C}\right)$ & Rhizome data & Seed data \\
\hline CA-2 & non-agricultural & 262 & 3.26 & yes & yes \\
TX-1 & agricultural & 923 & 2.7 & yes & yes \\
NM-4 & non-agricultural & 234 & -1.48 & yes & no \\
AL-10 & non-agricultural & 1456 & -0.64 & yes & yes \\
GA-6 & agricultural & 1197 & 0.69 & yes & yes \\
KS-4 & agricultural & 801 & -6.81 & yes & yes \\
TX-2 & agricultural & 1481 & 5.1 & yes & yes \\
AZ-2 & non-agricultural & 306 & 4.0 & yes & yes \\
FL-3 & non-agricultural & 1287 & 4.16 & yes & no \\
AZ-3 & non-agricultural & 199 & 4.29 & yes & yes \\
OH-7 & agricultural & 1022 & -7.75 & yes & no \\
KS-2 & non-agricultural & 771 & -6.74 & yes & yes \\
OH-1 & agricultural & 980 & -7.79 & yes & yes \\
NM-12 & agricultural & 458 & -5.04 & yes & yes \\
OH-8 & agricultural & 924 & -7.49 & yes & yes \\
NE-1 & non-agricultural & 790 & -9.45 & yes & yes \\
CA-1 & agricultural & 259 & 3.06 & yes & yes \\
TX-4 & non-agricultural & 462 & -5.21 & yes & yes \\
\hline
\end{tabular}

11 populations from each ecotype (22 in total) successfully germinated and established seedlings in the greenhouse (see detailed description below). We then transplanted two seedlings of each population to a common garden on Virginia Tech's campus to generate rhizomes for the experiment. Following 6 months of growth in the common garden, nine populations from each ecotype (18 total) produced sufficient rhizome material for the rhizome freezing experiment. For the seed freezing experiment, we began with the 18 populations used in the rhizome experiment. Of these, 3 populations did not germinate under any conditions and were excluded from data analyses. Thus, we analyzed rhizome cold tolerance of 18 ( 9 agricultural, 9 non-agricultural) populations and seed cold tolerance of 15 (8 agricultural, 7 non-agricultural) populations (see Table 1).

\section{Rhizome freezing experiment}

To release seeds from dormancy, we treated them with commercial strength sodium hypochlorite (Clorox Regular-Bleach, The Clorox Company, Oakland CA) for 4 hours followed by a 1 hour water rinse (Atwater et al. 2016). The prepared seeds were then placed in Petri dishes (one dish per population) with four saturated sheets of filter paper (Whatman 1003-055, GE Healthcare, Chicago IL). Upon radicle emergence, seeds were transferred to $1800 \mathrm{~cm}^{3}$ plastic pots filled with a potting mix (Miracle-Gro Moisture Control Potting Mix, Scotts Co LLC, Marysville OH) and allowed to establish for 4 weeks. All seedlings were then transplanted to 3.8 liter plastic pots $(16.5 \mathrm{~cm}$ diam., $20 \mathrm{~cm}$ depth) filled with the same potting mix. After 4 months of growth in the greenhouse, two individuals from each population were then transplanted to a common garden dominated by fine-loamy Alfisols and Ultisols, where they were randomly 
distributed on a $6 \mathrm{~m} \times 4.5 \mathrm{~m}$ grid. Plants were watered as necessary (once every $\sim 14$ days) and the ambient weed community was mechanically suppressed every 14 days as needed. Rhizomes were harvested from a single randomly-chosen individual from each population in December 2019.

Ten rhizome segments (10-20 mm long; containing only one node) from each plant (representing a single population) were sealed individually in capped $5 \mathrm{~mL}$ plastic culture tubes (Samco DCT, Thermo Fischer Scientific, Waltham MA) and submerged in cooling baths of 50:50 ethylene glycol:water solution for the cold treatments. We limited the rhizome segments to one node due to the known inverse relationship between segment length and probability of emergence in Johnsongrass (McWhorter 1972). Due to the number of cooling baths available, two populations - chosen at random from the common garden - were treated at one time for a total of four populations per day. This random selection of populations each day accounted for the five day spread in harvest times across all populations. Rhizome segment fresh biomass was recorded at this time for later use as a covariate to account for possible size differences. All treatments were administered for 6 hours, beginning at $5^{\circ} \mathrm{C}$ for 1 hour and dropping to one of the following temperatures: $0{ }^{\circ} \mathrm{C},-2{ }^{\circ} \mathrm{C},-4{ }^{\circ} \mathrm{C},-6{ }^{\circ} \mathrm{C}$, or $-10{ }^{\circ} \mathrm{C}$ for the remaining 5 hours. Acclimation periods - whether stepped or continuous - are standard protocol for tissue cold tolerance studies (Fiebelkorn and Rahman 2016; Peixoto and Sage 2016; Leuendorf et al. 2020), while the six-hour duration was chosen based on known lethality of $-3{ }^{\circ} \mathrm{C}$ to $-5^{\circ} \mathrm{C}$ temperatures for Johnsongrass well within 24 hours (Hull 1970) and we were interested in testing acute lethality only. Following treatment, all samples were acclimated to room temperature $\left(-24^{\circ} \mathrm{C}\right)$ for approximately 1 hour.

\section{Rhizome freezing data collection}

To determine the effect of cold treatments on rhizome viability, after treatment application all samples were removed from the plastic culture tubes and half of the rhizome segments (5) of each population's replicates were planted at $-2 \mathrm{~cm}$ depth in potting mix in plastic transplant trays (Vacuum Plug Tray, The H.C. Companies, Twinsburg OH). Trays consisted of ninety-eight $32 \mathrm{~cm}^{3}$ cells for the individual rhizome segment. Propagation trays were maintained in light and uncovered at room temperature $\left(-24^{\circ} \mathrm{C}\right)$ in the laboratory and were watered to maintain even moisture (every -3 days). We recorded binary success/failure to emerge, as well as days from treatment to emergence for each rhizome fragment sample.

The other half (5) of the replicates were submerged in $10 \mathrm{~mL}$ of deionized water in individual glass test tubes at $-24^{\circ} \mathrm{C}$ for electrolyte leakage assessment. Electrolyte leakage, in which $\mathrm{K}$ ions play a critical role (Demidchik et al. 2014), is an accepted proxy for cell death and tissue damage and has been used to estimate frost injury in other rhizomatous plant species (Peixoto and Sage 2016). After 24 hours, each of the samples was removed from the water, and we recorded specific conductance $(\mu \mathrm{S} / \mathrm{cm})$ of each sample's water, using a benchtop conductivity meter (AI502 EC700, Apera Instruments LLC, Columbus $\mathrm{OH}$ ). Each rhizome sample was then microwaved for 
150 seconds to trigger maximal electrolyte leakage. Microwaved samples were then returned to the same water containers where they had been for the preceding 24 hours. After another 24 hours, samples were removed again and specific conductance measured. We calculated relative conductivity $(\mathrm{RC})$, which represents the proportion of total possible electrolyte leakage that was induced by cold treatment application, using the equation:

$$
R C=E C_{t} / E C_{d}
$$

where $E C=$ electrical conductivity (i.e., specific conductance), $t=$ post-treatment, $d=$ dead (microwaved). This, in turn, served as a proxy for the proportion of rhizome tissue damaged by the treatment.

\section{Rhizome freezing statistical analyses}

We established a relationship between rhizome emergence and $\mathrm{RC}$ across all populations and temperatures with a logistic model and extracted the lethal dose (LD90) value - the $\mathrm{RC}$ value at which at least $90 \%$ of rhizomes do not emerge. We then fitted a Gompertz curve to the RC responses of each population to the treatment temperatures. Each of these curves was then used to inversely predict the temperature at which the LD90 RC value was achieved, yielding each population's 90\% lethal temperature (LT90) value. We then conducted stepwise linear regression of population LT90s on mean sample mass, as well as ecotype identity, MinT, MAP, and second order interactions, optimizing for the corrected Akaike Information Criterion (AICc) via backward selection. Mean sample mass was not subject to model reduction. The logistic model and LD90 extraction were performed in R (3.5.0; R Core Team 2018) using packages 'aod' (Lesnoff and Lancelot 2012), 'ggplot2' (Wickham 2016), 'MASS' (Venables and Ripley 2002), and 'popbio' (Stubben and Milligan 2007). Inverse prediction of LT90 and linear regression were performed with JMP Pro, Version 15 (SAS Institute, Inc., Cary, NC).

\section{Seed freezing experiment}

To conduct the seed freezing experiment, we selected the same 18 populations ( 9 agricultural, 9 non-agricultural) from the rhizome freezing experiment (Table 1), subsequently excluding 3 of them due to poor seed quality. Roughly 600 seeds per population were treated with commercial strength $(7.4 \%)$ sodium hypochlorite (Clorox Regular-Bleach, The Clorox Company, Oakland CA) for 4 hours followed by a 1 hour water rinse (Atwater et al. 2016) to break dormancy. The prepared seeds were then sealed in the same type of plastic culture tubes as the rhizome segments and each set of samples (one capsule of -600 seeds per population) was sealed in a plastic bag. We conducted several preliminary cold treatments using the same temperatures from the rhizome experiment. However, we observed no effect of these temperatures on germination percentage(GP) or mean time to germination (MGT) for any population. 
Thus, seed freezing treatments were applied at two levels $\left(-20^{\circ} \mathrm{C}\right.$ and $-85^{\circ} \mathrm{C}$, at $-100 \%$ relative humidity) for 24 hours. This duration was chosen based on a preliminary trial yielding non-zero germination of a single population chosen at random. We chose these treatment temperatures as we found no change in germinability between $0{ }^{\circ} \mathrm{C}$ and $-20^{\circ} \mathrm{C}$, and we were limited by equipment availability, as well as cooling capacities of the baths used in the rhizome experiment described above. For reference, the coldest air temperature ever recorded on Earth's surface is $-89.2{ }^{\circ} \mathrm{C}$ at the Vostok Station, Antarctica (Turner et al. 2009). Thus, our treatment temperatures should be viewed more as proof of concept for seed cold tolerance and less as a simulation of Johnsongrass seed response to freezing in the field. In other words, if seeds are capable of surviving 24 hours at $-85^{\circ} \mathrm{C}$, then range expansion is likely not limited by seed acute cold tolerance. The control was ambient temperature $\left(24^{\circ} \mathrm{C}\right)$ maintained for 24 hours. Following treatment, seeds from each population were distributed at random into 20seed replicates and placed in Petri dishes (one dish per replicate) with water-saturated filter paper (Whatman 1003-055, GE Healthcare, Chicago IL). Randomly sampled distribution of treated seeds into replicates was done in order to account for differences in micro-environments that may have been experienced at different locations in the capsule. The 270 Petri dishes (18 populations $\times 3$ treatments $\times 5$ replicates) were arranged in a randomized complete block design in the laboratory. Each replicate dish of 20 Johnsongrass seeds was sealed with Parafilm M laboratory film (Sigma-Aldrich, St. Louis, MO) to prevent excessive moisture loss.

\section{Seed freezing data collection}

We recorded the proportion of seeds in each replicate that successfully germinated (GP), as well as the number of days elapsed between treatment and germination. We also derived a mean time to germination (MGT) in days per seed for each 20-seed Petri dish. Data were collected until no new germination occurred, which was within 12 days of treatment application.

\section{Seed freezing statistical analyses}

We conducted mixed effects linear regression models of GP and MGT on experimental and populations origin variables. The model included fixed effects of ecotype, treatment temperature, MinT, and MAP, block as a random effect, as well as all possible second order interactions among the fixed effects. We then performed backward model selection, removing non-significant predictors in order to optimize AICc. Block was the only factor intentionally conserved in both models. All statistical analyses on seed freezing data were performed using JMP Pro, Version 15 (SAS Institute, Inc., Cary, NC).

\section{Data resources}

Experimental data are provided in an associated file (Suppl. material 1: Table S1). 
A

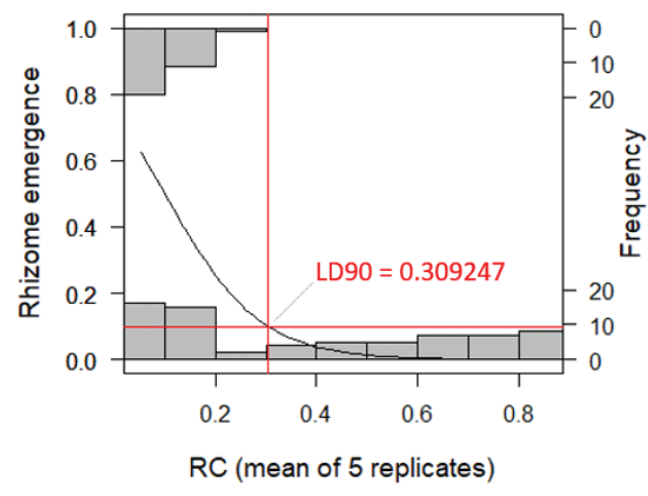

B

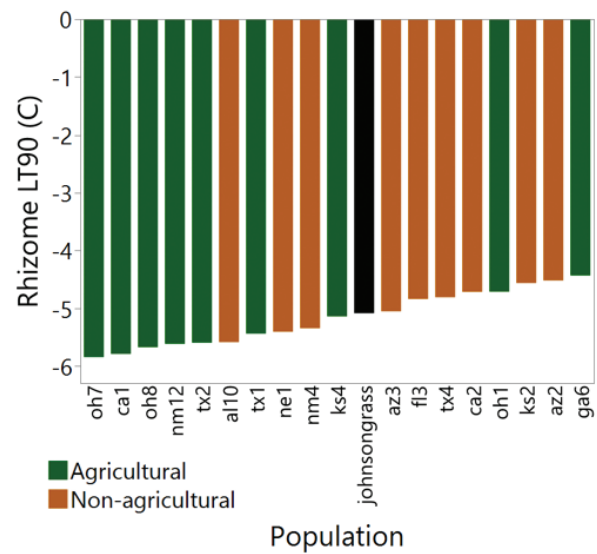

Figure 2. Plots of $\mathbf{A}$ the logit model of rhizome emergence response to 5-replicate relative conductivity (RC) means ( $\mathrm{p}=0.0081$ ), yielding a lethal dose for $90 \%$ of samples (LD90) of 0.309247 and B population and whole species lethal temperature for $90 \%$ of samples (LT90) values in degrees C based on rhizome $\mathrm{RC}$ values, in ascending order.

\section{Results}

\section{Rhizome freezing tolerance}

No rhizomes emerged after the $-10{ }^{\circ} \mathrm{C}$ treatment, but all other treatments $\left(-6{ }^{\circ} \mathrm{C}\right.$, $-4{ }^{\circ} \mathrm{C},-2{ }^{\circ} \mathrm{C}$ ) yielded partial emergence. Logistic regression of rhizome emergence on treatment temperature found a significant effect $(\mathrm{p}<0.0001)$ with a predicted LT90 of $-7.1^{\circ} \mathrm{C}$, which we calculated instead of the LT50 due to the baseline emergence rate (at the warmest temperatures) of $-50 \%$. Furthermore, rhizome emergence was erratic within populations due to node viability or other uncontrollable qualities, making results too variable for direct estimates of population-level LT90. Therefore, we used the logistic relationship between $\mathrm{RC}$ and emergence $(\mathrm{p}=0.0081$, Fig. $2 \mathrm{~A})$ to establish a species-wide RC value as a proxy for $90 \%$ failure to emerge (LD90). This LD90 value for the effect of $\mathrm{RC}$ on emergence was 0.3093 for all Johnsongrass populations. We then used this proxy to derive an LT90 from each population's RC-temperature response curve. Unlike the emergence data, $\mathrm{RC}$ data for each population were less variable and correlated well with Gompertz sigmoidal curves $\left(\mathrm{R}^{2}=0.94 \pm 0.01\right)$.

Rhizome LT90 was generally lower among agricultural $(-5.36 \pm 0.17)$ than nonagricultural $(-4.98 \pm 0.13)$ populations, but this relationship was not significant $(\mathrm{p}=0.079)$. Rhizome LT90 also did not correlate with MinT $(\mathrm{p}=0.640)$, MAP $(\mathrm{p}=0.848)$, or sample mass $(\mathrm{p}=0.478)$. Population LT90 values ranged from $-5.67^{\circ} \mathrm{C}$ $(\mathrm{OH}-8)$ to $-4.43{ }^{\circ} \mathrm{C}$ (GA-6), with overall Johnsongrass rhizome LT90 calculated at $-5.08^{\circ} \mathrm{C}$ (Fig. 2B). 
Table 2. Effect tests of each linear model of seed germination percentage (GP) and mean germination time (MGT) as reduced via backward stepwise selection for optimized Akaike Information Criterion $(\mathrm{AICc})$. Both response variables were log-transformed to meet model assumptions. Square brackets around variable names indicate variable locking prior to stepwise selection. Alpha level of significance indicated by ${ }^{* * *}=0.0005,{ }^{* *}=0.005,{ }^{*}=0.05$.

\begin{tabular}{lcccccccc}
\hline & \multicolumn{4}{c}{$\log _{\mathbf{1 0}}(\mathbf{G P})$} & \multicolumn{4}{c}{$\log _{\mathbf{1 0}}(\mathbf{M G T})$} \\
\cline { 2 - 9 } & $\mathbf{D F}$ & $\mathbf{S S}$ & $\mathbf{F}$ & $\mathbf{p}$ & DF & SS & F & P \\
\hline [Block] & 4 & 2.041 & 3.809 & 0.0526 & 4 & 0.191 & 3.101 & 0.0800 \\
Ecotype & 1 & 0.940 & 1.753 & 0.1872 & 1 & 0.073 & 1.190 & 0.2768 \\
MinT & 1 & 2.541 & 4.741 & $0.0308^{*}$ & 1 & 0.170 & 2.760 & 0.0985 \\
MAP & 1 & 5.667 & 10.576 & $0.0014^{* *}$ & 1 & 0.086 & 13.907 & $0.0003^{* *}$ \\
Treatment Temp & 1 & 17.980 & 33.552 & $<0.0001^{* * *}$ & 1 & 2.187 & 35.590 & $<0.0001^{* * *}$ \\
Ecotype*MinT & 1 & 2.845 & 5.309 & $0.0224^{*}$ & 1 & 0.687 & 11.176 & $0.001^{* *}$ \\
MinT*MAP & 1 & 14.554 & 27.159 & $<0.0001^{* * *}$ & 1 & 1.423 & 23.156 & $<0.0001^{* * *}$ \\
\hline
\end{tabular}

\section{Seed freezing tolerance}

Colder treatment temperatures decreased both GP and MGT ( $<<0.0001$; Table 2). Across all populations, on average, $31.2 \%$ of seeds in the control group germinated at $22{ }^{\circ} \mathrm{C}$. Seeds in the control group took an average of 0.45 days to germinate. The $-20{ }^{\circ} \mathrm{C}$ treatment resulted in $27.7 \%$ germination overall. Seeds treated at $-20{ }^{\circ} \mathrm{C}$ took an average of 0.88 days to germinate. The $-85^{\circ} \mathrm{C}$ treatment yielded $12.3 \%$ germination and took an average of 2.9 days to germinate.

There were marked population differences in germination percentage (GP) within and across treatments (Fig. 3). Across all temperatures, GP at the population level ranged from 4\% (KS-4) to 59\% (TX-2). The extremes in MGT across all temperatures were also represented by these two populations, ranging from 11.1 (KS-4) to 0.18 (TX-2). These two populations' composite GP and MGT ranks were not uniform across particular treatment temperatures. In the control group, AL-10 had the lowest mean germination at $1 \%$ while TX-2 was highest at $80 \%$. At $-20{ }^{\circ} \mathrm{C}$, KS-4 had the lowest mean GP of $6 \%$, while TX-4 was highest at $71 \%$. At $-85^{\circ} \mathrm{C}$, CA-2 had the lowest germination at $0 \%$ total, while OH-8 had the highest mean GP at $34 \%$.

\section{Effects of MinT, MAP, and ecotype on seed germination}

We found an interactive effect of MinT and MAP on both GP and MGT ( $p<0.0001$ for both; see Table 2). Cold/dry and warm/wet climates were associated with greater and faster germination than cold/wet and warm/dry climates (Fig. 4). Agricultural and non-agricultural populations responded inversely to each other to home temperature in both GP ( $\mathrm{p}=0.0224)$ and MGT $(\mathrm{p}=0.001)$ (Table 2$)$. GP of agricultural populations increased by $1.4 \%$ per degree $\mathrm{C}$ of home MinT, while that of non-agricultural populations decreased by $2.5 \%$ per degree $\mathrm{C}$ of home MinT (Fig. 5A). Similarly, the 


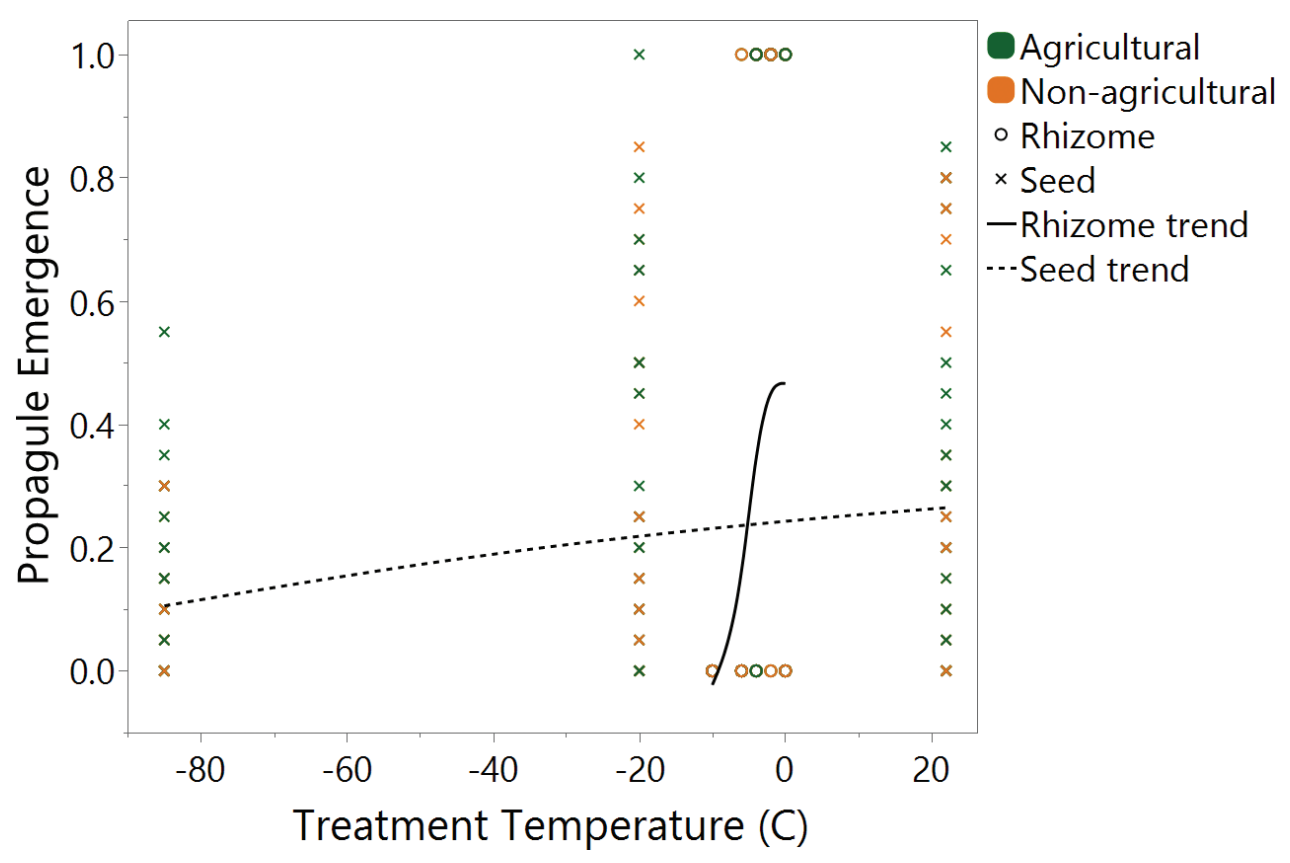

Figure 3. Seed and Rhizome emergence in response to their respective suites of treatment temperatures. Propagule type is indicated by marker shape and ecotype identity (agricultural vs. non-agricultural) is indicated by marker color. Markers allowed to overlap (not jittered) for legibility.

A

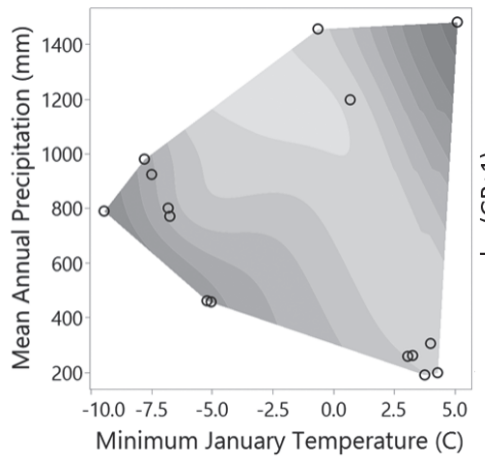

B

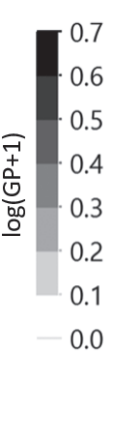

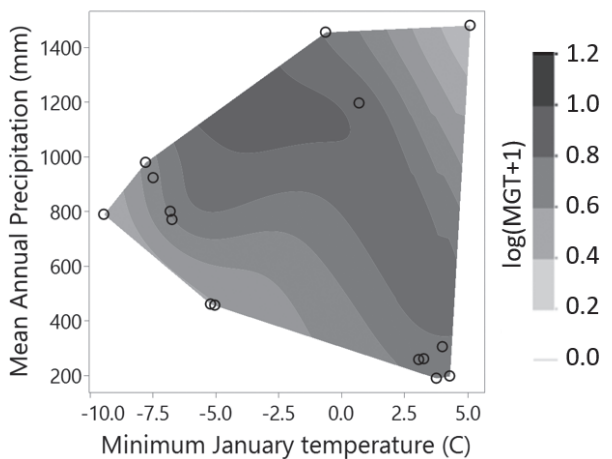

Minimum January temperature (C)

Figure 4. Interactive effects of $\mathbf{A}$ minimum January temperature (MinT) and mean annual precipitation (MAP) on germination percentage (GP) $(\mathrm{p}<0.0001)$ and $\mathbf{B}$ MinT and MAP on mean germination time $(\mathrm{MGT})(\mathrm{p}<0.0001)$ show greater and faster germination associated with populations from cold-and-dry and hot-and-humid climates. Both response variables are $\log _{10}$ transformed to meet model assumptions.

MGT of agricultural populations increased by 0.53 days for every degree of home MinT, while that of non-agricultural populations decreased by 5 days for every degree of home MinT (Fig. 5B). 
A

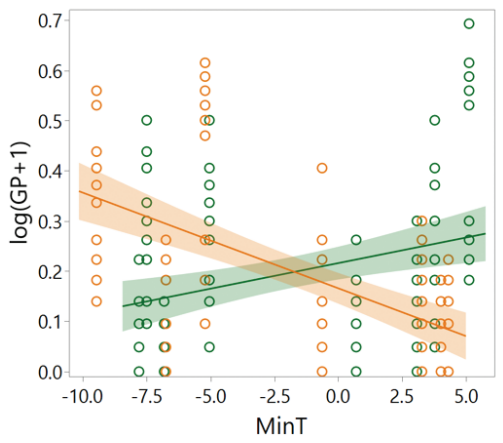

B

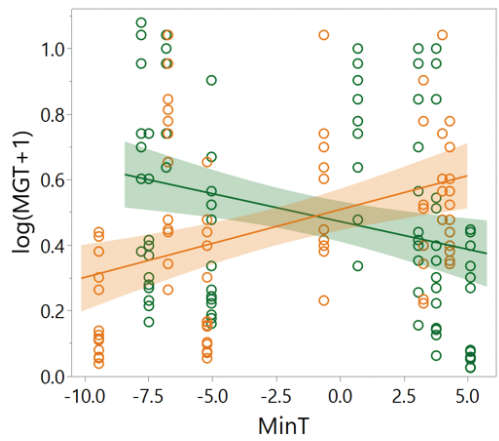

- Agricultural

- Non-agricultural

-Agricultural (trend)

- Non-agricultural (trend)

Figure 5. Interactive effects of $\mathbf{A}$ ecotype identity and minimum January temperature (MinT) on seed germination percentage (GP) ( $\mathrm{p}=0.0224)$ and $\mathbf{B}$ ecotype identity and MinT on mean germination time $(\mathrm{MGT})(\mathrm{p}<0.0001)$. Both response variables are $\log _{10}$ transformed to meet model assumptions.

\section{Discussion}

We found that both Johnsongrass seed and rhizome are affected by exposure to acute treatment temperature minima, but on very different scales. While rhizome emergence showed a sharp decline from $-50 \%$ emergence to non-viability in the vicinity of $-5^{\circ} \mathrm{C}$, seed germinability declined very gradually from $-25 \%$ to $10 \%$ across the gradient of 22 to $-85^{\circ} \mathrm{C}$. The rhizome survival threshold of approximately $-5^{\circ} \mathrm{C}$ confirmed Hull's (1970) finding of sharp decreases in rhizome survival between $-3{ }^{\circ} \mathrm{C}$ and $-5^{\circ} \mathrm{C}$ to the point of no viability, and appears consistent across the broad geographic range. Thus, we saw that overwintering potentials of seed and rhizome are vastly different, implying seed survivability in climates north of Johnsongrass's current range, far beyond known non-perenniating populations in southern Ontario (Warwick and Black 1983). Additionally, population differences based on home climate and ecotype were observed in seed, but not in rhizome. While these differences may be adaptive, it is all but certain that successful germination following $-85^{\circ} \mathrm{C}$ freezing treatment is not a trait selected for in the landscape, as Johnsongrass does not experience such extremes anywhere in, or near, its range; nor are there many places on Earth with such low temperatures. Interestingly, the impacts of home MinT on seed GP and MGT were mediated by ecotype identity, which may shed light on agricultural practices selecting for traits related to temperature and, by association, day length. The twofold $(50 \%$ vs. $25 \%$ ) difference in baseline (control) emergence of rhizome over seed, in conjunction with the latter's vast numerical superiority, echoes Atwater et al. (2017) conclusion that rhizome is more efficient than seed on a per-propagule basis, while seed is more efficient on a per-unit-carbon basis.

We found no differences in seed germination or rhizome emergence response and therefore no differences in cold tolerance - to freezing treatments based on home MAP and MinT. There were, however, inherent differences in seed germination response based on home MAP and MinT. This yielded a response surface where cool/ 
dry and warm/humid origin Johnsongrass populations germinated more and faster than cool/humid and warm/dry origin populations. It is possible that reduced and delayed germination on dry sites may be a conservative strategy selected for by drought stress, which can be especially damaging for seedlings, compared to seeds or mature plants (Schwinning et al. 2017). Meanwhile, an adaptation for proportionally higher germination in cold habitats may buffer against inevitable partial die-off in late frosts. Though associated more with growing season length than late frosts specifically, such a strategic adaptation has been found in the introduced range of the invader Ambrosia artemisiifolia (Leiblein-Wild et al. 2014). Earlier germination and leaf-out has been known to correspond to quicker recovery following freezing damage (Menzel et al. 2015). Therefore, one explanation for no difference in MGT based on home MinT could be that seedling Johnsongrass is unable to resprout following frost damage. This vulnerability may also contribute to inefficiencies in adapting to conditions at its northern range limits (Fletcher et al. 2020). Finally, earlier leaf-out as part of overall extended leaf phenology is a common strategy among invasive plants (Fridley 2012), though its ultimate utility in carbon gain is diminished at increasingly northern latitudes (O'Connell and Savage 2020).

No differences were found between agricultural and non-agricultural populations' seed or rhizome responses to freezing treatment temperatures, indicating no differences in cold tolerance based on ecotype identity. However, we again found inherent differences in GP and MGT based on home MinT as mediated by ecotype identity. Nonagricultural populations germinated more and faster than agricultural ones when originating from colder climates; however this did not translate to any differential response to our cold treatments. Given the smooth decrease in germinability from $+22^{\circ} \mathrm{C}$ to $-85^{\circ} \mathrm{C}$ treatments across all populations, it makes sense that population differences based on a MinT range of $-10{ }^{\circ} \mathrm{C}$ to $+5^{\circ} \mathrm{C}$ are unrelated to survival of $-85^{\circ} \mathrm{C}$ or even $-20^{\circ} \mathrm{C}$ treatments. Tolerance of the extreme cold could not have been selected for in the landscape, as Johnsongrass seed does not encounter these temperatures. Unfortunately, we were limited by available equipment to test temperatures between -10 and $-85^{\circ} \mathrm{C}$. We had posited that any differences in cold tolerance between ecotypes could be driven by energy assimilation and storage from a more favorable preceding season; however, this could not have been the case for seed, as we accounted for maternal effects by using only germplasm that had been grown out in a common environment for a generation.

Cold tolerance differences between seed and rhizome were so vast that they cannot be compared by LT90 values. Seed GP approached 0.1 (analogous to LT90) around $-85^{\circ} \mathrm{C}$ and no colder treatment was available, meaning that a true dose response curve could not be built for seed as it was for rhizome. This extreme cold tolerance across Johnsongrass populations informed us that seed freezing is likely not range limiting. Given no origin MAP or MinT differences in rhizome LT90, we also cannot test whether the annual climate niche is significantly different between populations. Instead, our evidence points to propagule pressure and phenology as likely factors of northern range limitation. Given the relatively high winter temperatures that rhizomes cannot survive, rhizome segments likely cease to be feasible propagules for range expansion in regions 
with climates similar to southern Ontario, where populations persist only via seed (Warwick and Black 1983). The general uniformity of rhizome LT90s across the species range suggests that rhizome cold tolerance is unlikely to adapt to colder climates in the future. Because we used only one cold acclimation regime across treatments, it is also possible that differences in acclimation capacity are present between populations, such as found in Miscanthus by Peixoto and Sage (2016). However, we have less reason to suspect such an effect in Johnsongrass, as Miscanthus is known to have a wider overall range in cold tolerance among genotypes (Fonteyne et al. 2016). It should also be noted that, even though GP values were low overall, the stochastic nature of these reductions and the very high significance level of model effects across 18 populations tell us that these correlations are robust. It is not unexpected to observe low overall seed germinability in weedy and invasive species that have evolved seed dormancy.

Dormant and non-dormant seeds are clearly not range limiting to Johnsongrass as a species, nor limited based on ecotype or home climate. In other words, seed from anywhere in the North American range can survive winter temperature minima anywhere on the continent. Given that Johnsongrass persists in places with colder winter temperatures than the rhizome LT90 of $-5^{\circ} \mathrm{C}$, thermal dynamics of soil are clearly a factor that prevents us from simply predicting cold temperature range limitation. Lack of apparent climate or ecotype adaptation of rhizome cold tolerance tells us that this may be a stable trait within the species, while an expanding "annual range" beyond the perennial range is feasible. However, even though seeds may always be cold tolerant, seedlings are likely to be much more vulnerable to stressors such as late frosts and droughts (Olson et al. 2018). Conceivably, more and faster germination as an adaptation to colder climates could be based on limited photosynthetically active radiation (PAR) of shorter summers. But why is this only seen in non-agricultural populations, while the inverse is true of agricultural ones? One driver of colder origin agricultural seed germinating less and slower than its non-agricultural counterpart could be greater winter/spring cold exposure in cropland due to bare soil (Snyder et al. 2015). It is also possible that early application of post-emergence herbicides could select for later germination. For example, a genetic link between herbicide resistance, dormancy and germination behavior is seen in the weedy grass Alopecurus myosuroides (Délye et al. 2013). Other agricultural factors could be at work, as seed phenology is known to be tremendously adaptive to cropping systems (Batlla et al. 2020). Molecular regulation of cold tolerance is currently an ongoing investigation with much progress made in understanding both the stress signaling and acclimation response involved (Ding et al. 2019).

One of the primary challenges in interpreting rhizome cold tolerance and forming hypotheses about continental distributions is the interaction of climate change with snow cover and, thereby, insulation of soils in winter. Rhizome carbohydrate storage, bud formation, survival, and phenology of spring emergence are known to be sensitive to winter snow depths (Lubbe et al. 2021). Specifically, reduced snowpack as a result of winter warming has been seen as particularly injurious to rhizomatous species populations, suppressing their competitive ability in herbaceous communities (Lubbe and Henry 2021). Winter warming, rather than summer warming, has been linked to 
major shifts in grassland primary production, species composition, and soil respiration (Kreyling et al. 2019), suggesting that future studies should also focus on temperature minima at population origins to study community assembly, as well as improved measures of perenniation, budbank, and multi-trait assessment (Lubbe et al. 2021).

\section{Conclusion}

By uncovering drastic differences in cold tolerance and between organs and populations, we are able to better understand their potential contributions to species distributions. We can begin to deduce which organs may or may not be limiting to overall plant stress tolerance and whether there are other physiological or phenological drivers of known range limits. Likewise, we can narrow possible drivers of range limitation and connect them to spatially explicit habitat parameters. However, we must be careful not to conflate experimentally isolated stress limits with distribution boundaries (Curtis and Bradley 2016). In this example of Johnsongrass seed versus rhizome cold tolerance, it becomes clearer whether or not a trait could have been acquired through selection. Namely, we see that, while seed is virtually unlimited by temperature minima in North America, we should not assume a lack of northern range limit. Likewise, we found rhizome cold tolerance to be less than what the perennial range would suggest, congruent with Curtis and Bradley's (2016) findings across many species. Furthermore, this approach has provided us with leads in terms of which organs, life stages, and stressors to investigate further. It also allowed us to characterize seed germinability and germination performance of different Johnsongrass ecotypes over a broad range of home climates.

We see that not all propagules of a plant respond similarly to all stresses - cold temperatures being a key example. In studying and managing invasive plants, this can inform our understanding of likely dispersal vectors. Our findings on Johnsongrass, in corroboration with Atwater et al. (2017), tell us that seed is a far more efficient, stress tolerant, and easily transported propagule than rhizome. This implies that, if most Johnsongrass populations are established by seed, we should expect ample genetic variation within and among landscapes compared to stands where clonal propagation is likely to occur. This genetic diversity contributes to the known intraspecific variation across the continent (Atwater et al. 2016, 2017; Sezen et al. 2016; Fletcher et al. 2020; Kelly et al. 2020), as well as its likelihood of adaptation to new habitats. At the same time, our study suggests some hard limits to cold adaptation, which is both ecologically interesting and informative for invasion risk assessment.

\section{Acknowledgements}

We thank Valerie Thomas and Brian Strahm for providing manuscript draft feedback. We thank Dave Mitchem for consultation on laboratory methods. We thank David Haak for laboratory equipment use. We thank Edward Gaines for common garden care. 
This work was partially supported by the Virginia Tech College of Agriculture and Life Sciences and the National Institute of Food and Agriculture Global Food Security CAP [2015-68004-23492 to JNB].

We would like to acknowledge support in the publication of this article from Virginia Tech's Open Access Subvention Fund.

\section{References}

Acciaresi HA, Guiamet JJ (2010) Below- and above-ground growth and biomass allocation in maize and Sorghum halepense in response to soil water competition. Weed Research 50: 481-492. https://doi.org/10.1111/j.1365-3180.2010.00794.x

Ambroise V, Legay S, Guerriero G, Hausman JF, Cuypers A, Sergeant K (2020) The roots of plant frost hardiness and tolerance. Plant and Cell Physiology 61: 3-20. https://doi. org/10.1093/pcp/pcz196

Atwater DZ, Kim W, Tekiela DR, Barney JN (2017) Competition and propagule density affect sexual and clonal propagation of a weed. Invasive Plant Science and Management 10: 17-25. https://doi.org/10.1017/inp.2017.4

Atwater DZ, Sezen UU, Goff V, Kong W, Paterson AH, Barney JN (2016) Reconstructing changes in the genotype, phenotype, and climatic niche of an introduced species. Ecography 39: 894-903. https://doi.org/10.1111/ecog.02031

Batlla D, Ghersa CM, Benech-Arnold RL (2020) Dormancy, a critical trait for weed success in crop production systems. Pest Management Science 76: 1189-1194. https://doi. org/10.1002/ps.5707

Bishop TR, Robertson MP, Van Rensburg BJ, Parr CL (2017) Coping with the cold: minimum temperatures and thermal tolerances dominate the ecology of mountain ants. Ecological Entomology 42: 105-114. https://doi.org/10.1111/een.12364

Boström U, Andersson L, Forkman J, Hakman I, Liew J, Magnuski E (2013) Seasonal variation in sprouting capacity from intact rhizome systems of three perennial weeds. Weed Research 53: 387-398. https://doi.org/10.1111/wre.12035

Charrier G, Ngao J, Saudreau M, Améglio T (2015) Effects of environmental factors and management practices on microclimate, winter physiology, and frost resistance in trees. Frontiers in Plant Science 6: 1-18. https://doi.org/10.3389/fpls.2015.00259

Chen XS, Li YF, Xie YH, Deng ZM, Li X, Li F, Hou ZY (2015) Trade-off between allocation to reproductive ramets and rhizome buds in Carex brevicuspis populations along a small-scale elevational gradient. Scientific Reports 5: 1-9. https://doi.org/10.1038/srep12688

Curtis CA, Bradley BA (2016) Plant distribution data show broader climatic limits than expertbased climatic tolerance estimates. PLoS ONE 11: 1-15. https://doi.org/10.1371/journal. pone.0166407

Délye C, Menchari Y, Michel S, Cadet É, Le Corre V (2013) A new insight into arable weed adaptive evolution: Mutations endowing herbicide resistance also affect germination dynamics and seedling emergence. Annals of Botany 111: 681-691. https://doi.org/10.1093/ aob/mct018 
Demidchik V, Straltsova D, Medvedev SS, Pozhvanov GA, Sokolik A, Yurin V (2014) Stressinduced electrolyte leakage: The role of K+-permeable channels and involvement in programmed cell death and metabolic adjustment. Journal of Experimental Botany 65: 12591270. https://doi.org/10.1093/jxb/eru004

Dietrich CC, Kreyling J, Jentsch A, Malyshev AV (2018) Intraspecific variation in response to magnitude and frequency of freeze-thaw cycles in a temperate grass. AoB PLANTS 10: 1-13. https://doi.org/10.1093/aobpla/plx068

Ding Y, Shi Y, Yang S (2019) Advances and challenges in uncovering cold tolerance regulatory mechanisms in plants. New Phytologist 222: 1690-1704. https://doi.org/10.1111/nph.15696

Dong L, Liang C, Li FY, Zhao L, Ma W, Wang L, Wen L, Zheng Y, Li Z, Zhao C, Tuvshintogtokh I (2019) Community phylogenetic structure of grasslands and its relationship with environmental factors on the Mongolian Plateau. Journal of Arid Land 11: 595-607. https://doi.org/10.1007/s40333-019-0122-6

Fiebelkorn D, Rahman M (2016) Development of a protocol for frost-tolerance evaluation in rapeseed/canola (Brassica napus L.). Crop Journal 4: 147-152. https://doi.org/10.1016/j. cj.2015.11.004

Fletcher RA, Varnon KM, Barney JN, Smith M (2020) Climate drives differences in the germination niche of a globally distributed invasive grass. Journal of Plant Ecology 13: 195-203. https://doi.org/10.1093/jpe/rtz062

Fonteyne S, Muylle H, De Swaef T, Reheul D, Roldán-Ruiz I, Lootens P (2016) How low can you go?-Rhizome and shoot frost tolerance in miscanthus germplasm. Industrial Crops and Products 89: 323-331. https://doi.org/10.1016/j.indcrop.2016.05.031

Fridley JD (2012) Extended leaf phenology and the autumn niche in deciduous forest invasions. Nature 485: 359-362. https://doi.org/10.1038/nature11056

Gardner AS, Maclean IMD, Gaston KJ (2019) Climatic predictors of species distributions neglect biophysiologically meaningful variables. Diversity and Distributions 25: 1318-1333. https://doi.org/10.1111/ddi.12939

Greiser C, Hylander K, Meineri E, Luoto M, Ehrlén J (2020) Climate limitation at the cold edge: contrasting perspectives from species distribution modelling and a transplant experiment. Ecography: 637-647. https://doi.org/10.1111/ecog.04490

Grewell BJ, Futrell CJ, Iannucci MT, Drenovsky RE (2019) Resprouting potential of rhizome fragments from invasive macrophyte reveals superior colonization ability of the diploid congener. AoB PLANTS 11: 1-10. https://doi.org/10.1093/aobpla/plz071

Hull RJ (1970) Germination control of johnsongrass rhizome buds. Weed Science 18: 118121. https://doi.org/10.1017/S0043174500077481

Kelly S, Fletcher RA, Barney JN (2020) Intraspecific, ecotypic and home climate variation in photosynthetic traits of the widespread invasive grass Johnsongrass. AoB PLANTS 12: 1-9. https://doi.org/10.1093/aobpla/plaa015

Körner C, Basler D, Hoch G, Kollas C, Lenz A, Randin CF, Vitasse Y, Zimmermann NE (2016) Where, why and how? Explaining the low-temperature range limits of temperate tree species. Journal of Ecology 104: 1076-1088. https://doi.org/10.1111/1365-2745.12574

Kotta J, Vanhatalo J, Jänes H, Orav-Kotta H, Rugiu L, Jormalainen V, Bobsien I, Viitasalo M, Virtanen E, Sandman AN, Isaeus M, Leidenberger S, Jonsson PR, Johannesson K (2019) 
Integrating experimental and distribution data to predict future species patterns. Scientific Reports 9: 1-14. https://doi.org/10.1038/s41598-018-38416-3

Kozlowski TT (1992) Carbohydrate sources and sinks in woody plants. The Botanical Review 58: 107-222. https://doi.org/10.1007/BF02858600

Kreyling J, Grant K, Hammerl V, Arfin-Khan MAS, Malyshev AV, Penuelas J, Pritsch K, Sardans J, Schlotter M, Schuerings J, Jentsch A, Beierkuhnlein C (2019) Winter warming is ecologically more relevant that summer warming in a cool-temperate grassland. Scientific Reports 9: e14632. https://doi.org/10.1038/s41598-019-51221-w

Lakoba VT, Barney JN (2020) Home climate and habitat drive ecotypic stress response differences in an invasive grass. AoB Plants 1: 1-27. https://doi.org/10.1093/aobpla/plaa062

Leiblein-Wild MC, Kaviani R, Tackenberg O (2014) Germination and seedling frost tolerance differ between the native and invasive range in common ragweed. Oecologia 174: 739-750. https://doi.org/10.1007/s00442-013-2813-6

Leuendorf JE, Frank M, Schmülling T (2020) Acclimation, priming and memory in the response of Arabidopsis thaliana seedlings to cold stress. Scientific Reports 10: 1-11. https:// doi.org/10.1038/s41598-019-56797-x

Li X, Liang E, Gričar J, Rossi S, Čufar K, Ellison AM (2017) Critical minimum temperature limits xylogenesis and maintains treelines on the southeastern Tibetan Plateau. Science Bulletin 62: 804-812. https://doi.org/10.1016/j.scib.2017.04.025

Lubbe FC, Henry HAL (2021) The role of perennation traits in plant community soil frost stress responses. Annals of Botany 126: 873-881. https://doi.org/10.1093/aob/mcaa104

Lubbe FC, Klimesova J, Henry HAL (2021) Winter belowground: Changing winters and the perennating organs of herbaceous plants. Functional Ecology 00: 1-13. https://doi. org/10.1111/1365-2435.13858

Malyshev AV, Henry HAL, Kreyling J (2014) Relative effects of temperature vs. photoperiod on growth and cold acclimation of northern and southern ecotypes of the grass Arrhenatherum elatius. Environmental and Experimental Botany 106: 189-196. https://doi. org/10.1016/j.envexpbot.2014.02.007

McWhorter C (1972) Factors affecting johnsongrass rhizome production and germination. Weed Science 20: 41-45. https://doi.org/10.1017/S0043174500034901

Menzel A, Helm R, Zang C (2015) Patterns of late spring frost leaf damage and recovery in a European beech (Fagus sylvatica L.) stand in south-eastern Germany based on repeated digital photographs. Frontiers in Plant Science 6: 1-13. https://doi.org/10.3389/fpls.2015.00110

Mitskas MB, Tsolis CE, Eleftherohorinos IG, Damalas CA (2003) Interference between corn and johnsongrass (Sorghum halepense) from seed or rhizomes. Weed Science 51: 540-545. https://doi.org/10.1614/0043-1745(2003)051[0540:IBCAJS]2.0.CO;2

O'Connell E, Savage J (2020) Extended leaf phenology has limited benefits for invasive species growing at northern latitudes. Biological Invasions 22: 2957-2974. https://doi. org/10.1007/s10530-020-02301-w

Olson ME, Soriano D, Rosell JA, Anfodillo T, Donoghue MJ, Edwards EJ, León-Gómez C, Dawson T, Julio Camarero Martínez J, Castorena M, Echeverría A, Espinosa CI, Fajardo A, Gazol A, Isnard S, Lima RS, Marcati CR, Méndez-Alonzo R (2018) Plant height and hydraulic vulnerability to drought and cold. Proceedings of the National Academy 
of Sciences of the United States of America 115: 7551-7556. https://doi.org/10.1073/ pnas. 1721728115

Oraee A, Tehranifar A, Nezami A, Shoor M (2020) The effects of three levels of irrigation water on the improvement of cold tolerance of acclimated viola. Acta Physiologiae Plantarum 42: e111. https://doi.org/10.1007/s11738-020-03095-z

Peixoto M de M, Sage RF (2016) Improved experimental protocols to evaluate cold tolerance thresholds in Miscanthus and switchgrass rhizomes. GCB Bioenergy 8: 257-268. https:// doi.org/10.1111/gcbb.12301

Pompeiano A, Vita F, Miele S, Guglielminetti L (2015) Freeze tolerance and physiological changes during cold acclimation of giant reed [Arundo donax (L.)]. Grass and Forage Science 70: 168-175. https://doi.org/10.1111/gfs.12097

Ramesh K, Matloob A, Aslam F, Florentine SK, Chauhan BS (2017) Weeds in a changing climate: Vulnerabilities, consequences, and implications for future weed management. Frontiers in Plant Science 8: 1-12. https://doi.org/10.3389/fpls.2017.00095

Rohde A, Bhalerao RP (2007) Plant dormancy in the perennial context. Trends in Plant Science 12: 217-223. https://doi.org/10.1016/j.tplants.2007.03.012

Roiloa SR, Retuerto R (2016) Effects of fragmentation and seawater submergence on photochemical efficiency and growth in the clonal invader Carpobrotus edulis. Flora: Morphology, Distribution, Functional Ecology of Plants 225: 45-51. https://doi.org/10.1016/j. flora.2016.10.002

Sage RF, De Melo Peixoto M, Friesen P, Deen B (2015) C4 bioenergy crops for cool climates, with special emphasis on perennial C4 grasses. Journal of Experimental Botany 66: 41954212. https://doi.org/10.1093/jxb/erv123

Sánchez-Fernández D, Aragón P, Bilton DT, Lobo JM (2012) Assessing the congruence of thermal niche estimations derived from distribution and physiological data. A test using diving beetles. PLoS ONE 7(10): e48163. https://doi.org/10.1371/journal.pone.0048163

Schmid B, Bazzaz FA (1992) Growth responses of rhizomatous plants to fertilizer application and interference. Oikos 65: 13-24. https://doi.org/10.2307/3544882

Schwinning S, Meckel H, Reichmann LG, Polley HW, Fay PA (2017) Accelerated development in Johnsongrass seedlings (Sorghum halepense) suppresses the growth of native grasses through sizeasymmetric competition. PLoS ONE 12: 1-18. https://doi.org/10.1371/journal.pone.0176042

Sezen UU, Barney JN, Atwater DZ, Pederson GA, Pederson JF, Chandler JM, Cox TS, Cox S, Dotray P, Kopec D, Smith SE, Schroeder J, Wright SD, Jiao Y, Kong W, Goff V, Auckland S, Rainville LK, Pierce GJ, Lemke C, Compton R, Phillips C, Kerr A, Mettler M, Paterson AH (2016) Multi-phase US spread and habitat switching of a post-columbian invasive, Sorghum halepense. PLoS ONE 11: 1-14. https://doi.org/10.1371/journal.pone.0164584

Slewinski TL (2012) Non-structural carbohydrate partitioning in grass stems: a target to increase yield stability, stress tolerance, and biofuel production. Journal of Experimental Botany 63(13): 4647-4670. https://doi.org/10.1093/jxb/ers124

Snyder K, Grant A, Murray H, Wolff B (2015) The effects of plastic mulch systems on soil:Temperature and moisture in central Ontario. HortTechnology 25: 162-170. https:// doi.org/10.21273/HORTTECH.25.2.162 
Turner J, Anderson P, Lachlan-Cope T, Colwell S, Phillips T, Kirchgaessner A, Marshall GJ, King JC, Bracegirdle T, Vaughan DG, Lagun V, Orr A (2009) Record low surface air temperature at Vostok station, Antarctica. Journal of Geophysical Research Atmospheres 114: 1-14. https://doi.org/10.1029/2009JD012104

Warwick SI, Black LD (1983) The biology of canadian weeds. 61. Sorghum halepense (L.) Pers. Canadian Journal of Plant Science 1014: 997-1014. https://doi.org/10.4141/cjps83-125

Washburn JD, Whitmire DK, Murray SC, Burson BL, Wickersham TA, Heitholt JJ, Jessup RW (2013) Estimation of rhizome composition and overwintering ability in perennial sorghum spp. Using Near-Infrared Spectroscopy (NIRS). Bioenergy Research 6: 822-829. https://doi.org/10.1007/s12155-013-9305-8

Weber JF, Kunz C, Peteinatos GG, Zikeli S, Gerhards R (2017) Weed control using conventional tillage, reduced tillage, no-tillage, and cover crops in organic soybean. Agriculture (Switzerland) 7(5): 43. https://doi.org/10.3390/agriculture7050043

Wingler A (2015) Comparison of signaling interactions determining annual and perennial plant growth in response to low temperature. Frontiers in Plant Science 5: 1-9. https://doi. org/10.3389/fpls.2014.00794

Zhou J, Li HL, Alpert P, Zhang MX, Yu FH (2017) Fragmentation of the invasive, clonal plant Alternanthera philoxeroides decreases its growth but not its competitive effect. Flora: Morphology, Distribution, Functional Ecology of Plants 228: 17-23. https://doi. org/10.1016/j.flora.2017.01.007

\section{Supplementary material I}

\section{Table S1}

Authors: Vasiliy T. Lakoba, Gregory E. Welbaum, John R. Seiler, Jacob N. Barney

Data type: propagule emergence

Explanation note: A table of emergence response by population, temperature, and propagule type.

Copyright notice: This dataset is made available under the Open Database License (http://opendatacommons.org/licenses/odbl/1.0/). The Open Database License $(\mathrm{ODbL})$ is a license agreement intended to allow users to freely share, modify, and use this Dataset while maintaining this same freedom for others, provided that the original source and author(s) are credited.

Link: https://doi.org/10.3897/neobiota.70.64614.suppl1 